\title{
Main Technical Differences in the Processing of Broilers: A Comparison between Slaughterhouses in Brazil and
}

\section{UK}

\author{
Ricardo Lacava Bailone ${ }^{1}$, Roberto de Oliveira Roça ${ }^{2}$, Luis de Aguiar ${ }^{3}$ and Moira Harris ${ }^{4}$ \\ 1. Universidade Estadual Paulista Júlio de Mesquita Filho (UNESP)-Botucatu, SP and Harper Adams University, Newport, United \\ Kingdom/Federal Inspection Agent of the Brazilian Ministry of Agriculture, Livestock and Supply, São Paulo 13.565-580, Brazil \\ 2. Department of Animal Health, Veterinary Public Health and Food Safety, Universidade Estadual Paulista Júlio de Mesquita Filho \\ (UNESP)-Botucatu, São Paulo 18.610-307, Brazil
}

3. Food Marketing and Food Security, Department of Food Science, Harper Adams University, Newport, Shropshire TF10 8NB, United Kingdom

4. Animal Science, Department of Animal Production and Welfare, Harper Adams University, Newport, Shropshire TF10 8NB, United Kingdom

\begin{abstract}
Rapid technological advances in chicken processing in plants around the world have meant that different techniques are being employed regarding the slaughter's flow process. This paper aimed to compare and contrast systems and practices in two large slaughterhouses - one in UK and the other in Brazil. Annotated observations were made during inspection visits to chicken slaughterhouses in the two countries between 2014 and 2016. Whilst there were similarities in the two systems, there are also clear differences. The Brazilian case is evidently adapted for a more tropical condition, rather than the temperate one in UK. The handling practices of birds used during transportation, waiting, stunning as well as pre-cooling differ in techniques employed and consequently likely their efficiencies. In UK, the practices are more geared towards water and energy saving. The difference in market conditions and the length of the respective supply chains also determine the type of primary packaging used in final products. Both countries adhere to similar rulings applied to slaughterhouses. However, in the Brazilian case, it tended to comply with mainly external market demands. In conclusion, managers in the Brazilian poultry system could consider looking into adopting some of the practices used in UK, such as cage/crate dimension which reduce bird's lesions and bruises; the use of stunning by modified atmosphere and pre-cooling for resource efficiency reasons and improvement in animal welfare. Finally, when distances between sites of production and consumption are great such as in Brazil, the use of modified atmosphere technology could be also further explored to ensure better quality of the final product.
\end{abstract}

Key words: Abattoir, chicken, food technology, food security, poultry.

\section{Introduction}

In 2015, according to the United States Department of Agriculture (USDA), Brazil was ranked the second behind US in the production, and the first in the export of broilers in the world [1]. Broiler production in the country has increased steadily since 1997 , reaching an annual slaughter of about six billion birds. The

Corresponding author: Ricardo Lacava Bailone, Ph.D. student, research fields: food science and agri-food supply chain management. accumulated weight of carcasses in the same period reached 13.14 million tonnes, up 5\% compared to 2014 [2]. According to Eurostat [3] in 2015, the European Union had also produced some 13 million tonnes of poultry meat within four countries, leading the production responsible for over half of the EU total poultry production as follows: Poland (13.9\%), France (12.9\%), UK (12.6\%) and Germany (11.8\%), respectively.

Despite Brazil as the reference in the processing of 
broilers worldwide, those in the sector still tend to search and acquire new technologies and animal husbandry techniques from more economically developed countries, such as USA or those of the European Union (EU). Moreover, in spite of the sanitary and animal welfare legislations, to some extent, being harmonised between these countries in order to comply with international guidelines, it is, nonetheless, possible to identify some key differences in the processing of broilers between the practice in slaughterhouses in UK and Brazil.

In UK's slaughterhouse context, adhering to animal welfare standards is considered highly important owing to demand from pressure groups, consumers and food retailers. Furthermore, waste loses are avoided at all cost. Loses of whole or part of carcasses, as well as the excessive use of water during the processing, would have a detrimental impact on the slaughterhouse profitability. The Water Industry Act of 1991 [4] and the Water Act of 2014 [5] tightly control the use and the recycling of water as part of the environmental legislation in UK. Furthermore, the Department for Food and the Environment (DEFRA) regulates the disposal of animal by-products as the discarding of bird carcasses [6]. The purpose of this paper aimed to compare and contrast systems and practices in slaughterhouses between UK and Brazil.

\section{Materials and Methods}

A comparison of systems and processes was carried out based on observations made between two large broilers' processing plants in two different countries (one in a more economically developed country and the other one in an emerging country). Observations were made following the slaughter's flowchart (Fig. 1). Comparisons were made in respect of the technologies used as well as the legislation followed in the two sites.

For UK case, data were collected from major poultry slaughterhouse located in the West Midlands

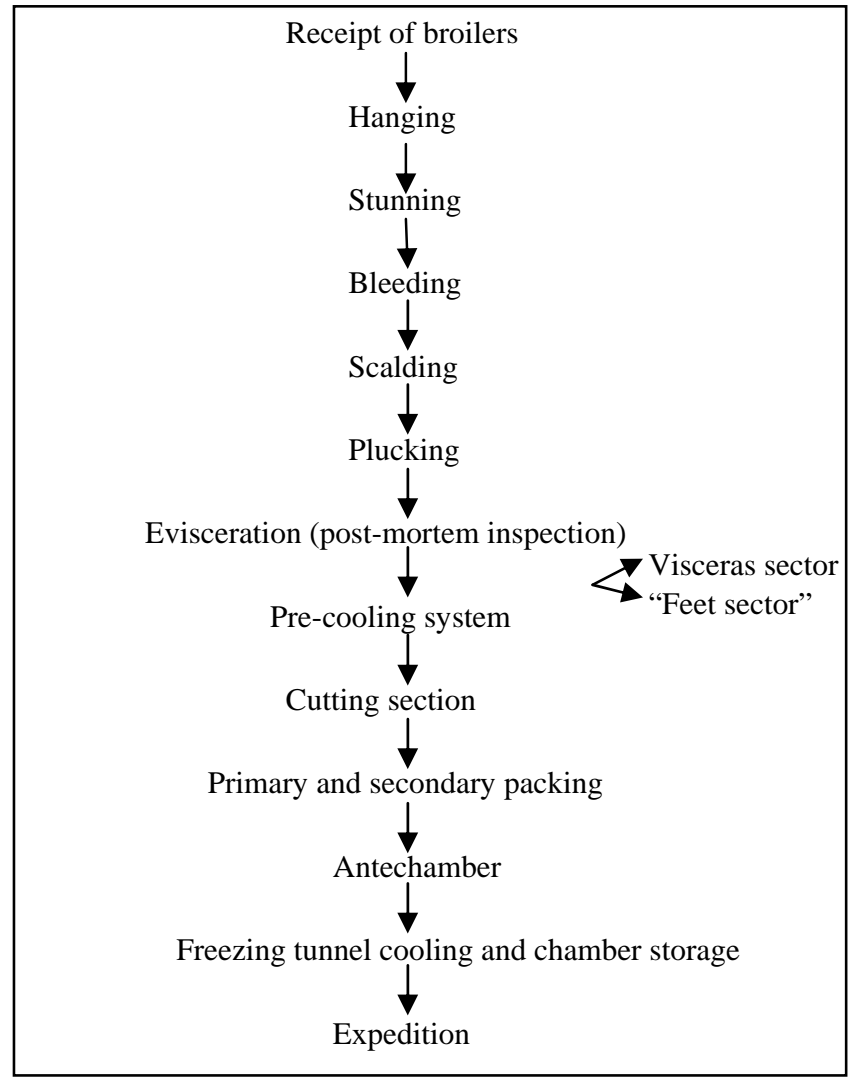

Fig. 1 Flowchart of the slaughter of broilers.

during visits between the autumn of 2015 and the spring of 2016. In Brazil, observations were made based on a typical large-scale slaughterhouse located in the South-Eastern region during 2014. The size and capacity of both plants were similar, i.e., processing about 150,000 broilers a day in a speed of 10,000 broilers/h in two shifts of $8 \mathrm{~h}$.

\section{Results and Discussion}

\subsection{Pre-processing}

There are clear distinctions between the two countries regarding the transportation of the birds from the farm to the slaughterhouse. In Britain, live birds are transported in modules of eight large open crates which are mounted on to frames. There is no information for the minimum crate size, however, the typical EU legislation does control the space per animal taken from the EU transport regulation [7] (beginning with $180-200 \mathrm{~cm}^{2}$ for poultries weighing 
less than $1.6 \mathrm{~kg}$ and finishing with $105 \mathrm{~cm}^{2}$ for poultries weighing more than $5 \mathrm{~kg}$ ), and it may vary depending not only on the weight and the size of the birds, but also on their physical conditions, the meteorological conditions and the likely journey time. The usual crates or drawers in UK are higher in volume and lower in height compared with that in Brazil. It does not allow for one broiler to climb over the other, thus avoiding possible fractures, bruises and injuries during transportation. The crates provide the birds with significant better ventilation, resulting overall reduced mortality at arrival. Yet, the Brazilian crate allows for the birds to climb on each other, especially when the crater's density is high. During the summer months, overall mortality and injuries escalates owed to the lack of ventilation the birds have adding to stress and loss of water. In a study, Bailone et al. [8] compared the indices of the typical slaughterhouses in Brazil and UK, and found that the mortality of birds in Brazil at arrival caused during transportation by thermal stress or overcrowding was five times higher than that of a slaughterhouse in UK (0.72\% and $0.13 \%$, respectively). Conversely, the Brazilian cages, despite their smaller dimension (26 $\mathrm{cm} \times 56.5 \mathrm{~cm} \times 76 \mathrm{~cm}$ ), allows for an animal to rest on top of the other, especially when the density of cages is high with damaging results also caused by the lack of ventilation, especially during the summer months.

\subsection{At Arrival}

In Brazil, the lorries arrive at the slaughterhouse and await to be unloaded in the waiting shed. Care is taken for the birds to remain sheltered from the sun, under sufficient ventilation, and humidity control is carried out so that the birds are not affected by high temperatures. In the English case, the lorries wait at unsheltered docks (Table 1). However, each dock is covered by side curtains to protect the birds mainly from the cold wind and low temperatures. In both countries, a break of $2 \mathrm{~h}$ is recommended at arrival, when the ante-mortem inspection is realized by the respective health service veterinarian.

\subsection{Stunning}

After the $2 \mathrm{~h}$ time lapse, the birds are unloaded, thus entering the slaughterhouse to start the processing. In England, the predominant stunning method used is modified atmosphere, which has been replacing electronarcosis. In the current method, the crates are unloaded from the lorries pass through a compartment with modified atmosphere consisting of $70 \%-80 \%$ $\mathrm{CO}_{2}$ for about $6.5 \mathrm{~min}$. The birds are stunned and killed still inside the crates, thus preventing them to regain consciousness before the bleeding stage. This method considerably reduces the birds' stress due to handling and hanging on the shackle line. This method is also beneficial for those birds which might be still alive, thus reducing overall animal stress of being manipulated and hung on the shackle line. In Brazil, the electronarcosis does not kill the birds which are still alive when being immersed in a tub of water under controlled amperage and voltage. When electronarcosis is used, the recommended time between stunning and bleeding should be no more than $10-15 \mathrm{~s}$ (in Brazil it is about $12 \mathrm{~s}$ ), and when the modified atmosphere is used, there should be no more than a $30 \mathrm{~s}$ gap between stunning and bleeding. The use of modified controlled atmosphere as a stunning method has been recognized by governments and animal protection organizations throughout Europe as an acceptable alternative to replace electronarcosis by immersion in water [9-11]. In addition to water savings, this method is considered to provide higher animal welfare. In the Netherlands, for example, electronarcosis by immersion in water has been replaced by gas stunning due to low efficiency of that method [12]. According to Gerritzen et al. [12], the challenge was to find an acceptable balance between the intensity and duration of stunning, which did promote the minimal animal suffering, showing that chickens stunned by exposure to two gradual increased 
Table 1 Main technical differences in the processing of boilers.

\begin{tabular}{|c|c|c|}
\hline Technical & Brazil & UK \\
\hline Pre-processing & Clearly adapted for the tropical condition & Clearly adapted for the temperate condition \\
\hline Handling & Manual & Mechanical \\
\hline At arrival & $\begin{array}{l}\text { Sheltered from the sun, under sufficient } \\
\text { ventilation and humidity control }\end{array}$ & $\begin{array}{l}\text { Unsheltered docks. Each dock is covered by side curtains to protect } \\
\text { the birds mainly from the cold wind and low temperatures }\end{array}$ \\
\hline Stunning & Electronarcosis & Modified atmosphere \\
\hline Carcass chilling & $\begin{array}{l}\text { Pre-cooling system by immersion in cold } \\
\text { water }\end{array}$ & Pre-cooling system by cold air \\
\hline Packing & Conventional and vacuum & Conventional, vacuum and modified atmosphere \\
\hline Legislation & Very similar in both countries & Very similar in both countries \\
\hline
\end{tabular}

$\mathrm{CO}_{2}$ concentrations were more effective. At the British slaughterhouse, after unloading the crates, they undergo a mechanical washing, followed by a manual cleaning, with the aid of hand brushes and pressured water. Disinfection takes place to reduce microbiological contamination, such as Campylobacter and Salmonella.

\subsection{Bleeding}

After the stunning, the birds, suspended by their feet, are bled out using a rotary saw following the "modified Kosher" method. For a complete bleeding out, similarly to the Brazilian legislation, the animals must remain suspended for at least $3 \mathrm{~min}$ before moving to the next stage. In both countries, for those birds whose carotids arteries have not been cut deeply enough by the bleeder disk, an employee carries out manual bleeding in the neck, which effectively kills the animal. The employee who carries out a visual inspection would normally handle two sharp knives which are used alternately by replacing one into heated water at least $82{ }^{\circ} \mathrm{C}$ in England and $85{ }^{\circ} \mathrm{C}$ in Brazil for the purpose of sterilization of the blades, whilst using the other to cut the artery. In UK, because the broilers had not yet been removed from the crates while not yet stunned, the dead on arrival count is made after stunning and before hanging them in the shackle line for bleeding. The count is carried out through manual checking the bird's body temperature by touch. This is possible because those birds that have already arrived dead at the slaughterhouse, tend to be more rigid and naturally cold. However, the visual inspection held in Brazil before the birds hanging is considered to be more effective. In the Brazilian case, an employee does not require much training when inspecting mortality in a line of 10,000 chickens/h. A temperature inspection using touch is prone to not be precise.

\subsection{Scalding and Evisceration}

In UK, the scalding stage occurs similarly to that in Brazil. Carcasses are continuously dipped in a tank with warm water at about $56{ }^{\circ} \mathrm{C}$ for 3 min to loosen their feathers. Following this, the feather removal method employed in both countries is very similar. After passing through the plucking machine, the British system provides for the carcasses to be hung one by one on the shackle line to be rinsed by a jet of high pressure water as part of final cleaning. The high pressure water removes the remaining feathers, soil and any dirtiness that might still remain. Employees use shovels to collect feathers and solids on the floor in "dirty areas", as well as other dirtiness in the "clean areas". This seems to be a very efficient way in removing the waste, which is collected into stainless steel containers and in turn sent to meat rendering plants. When not in use, shovels, rakes and other materials used in the cleaning remain immersed in disinfectant solution.

\subsection{Evisceration and Inspection}

In UK case, the carcasses, which at this stage have their feet removed and are hung by the knee joint, go through various types of mechanical removal of 
viscera in the evisceration room. The processing line separates the employee from the machines by stainless steel railings. This avoids the human contact with mechanical parts, thus minimizing accidents. Along the line, the employees have only a few key points of access to the carcass to perform some manual and technical work, such as inspection. The inspection is carried out by an official from the Food Standards Agency (FSA), which is the British government agency responsible for general food regulation and legislation [13]. The FSA employs veterinarians and meat inspectors, who enforce the compliance of standards regarding the hygiene of the meat, animal welfare and other statutory rules. In both countries, veterinarians take preventive and corrective actions to ensure compliance, which may include verbal or written notices of non-compliance, and where necessary, the application of penalties. In Brazil, meat inspection is regulated by the Ministry of Agriculture and Food Supply, and the inspection service is organized at municipal, state or federal levels. Federal inspection is usually used by abattoirs licensed to export. The post-mortem inspection itself is similarly performed in both countries. The carcass is inspected internally and externally, as well as the viscera and the correlation carcass-viscera is checked. The framework for checking pathological conditions is also very similar in both countries. In UK, it includes the checking for aerosaculitis, pericarditis, perihepatitis, abnormal coloring, machinery damage, ascites, infection, injury, cellulitis, cachexia, dermatitis, peritonitis, tumor, myositis, septicemia, arthritis, salpingitis and isolated affections of the heart and liver. British consumers have no longer got the taste for eating chicken viscera and feet, thus not on display at supermarkets. Chicken viscera, neck, head and feet are sent to either rendering plant or pet food processing. Nevertheless, the Brazilian population still has a taste for broilers' viscera, such as heart, gizzard and liver. The neck, head and feet are usually exported to African countries and China.

\subsection{Carcass Chilling and Added Water}

Regarding the pre-cooling system, Brazilian legislation recommends the use of two tanks of ice water and/or ice, the first to act as a pre-chiller and the second as chiller. Each tank should have a minimal constant renewal of $1.5 \mathrm{~L} /$ carcass in the pre-chiller (the maximum immersion time of 30 min per carcass) and $1.0 \mathrm{~L} /$ carcass in the chiller (no restriction on the immersion time). After passing through the cooling system, the carcass must present a maximum temperature of $7{ }^{\circ} \mathrm{C}$ [14]. In UK, pre-cooling by cold air is mainly used (Table 1). According to European legislation, the carcass must leave the pre-cooling with a maximum temperature of $4{ }^{\circ} \mathrm{C}$, with no set requirement as for time [10]. In that kind of system, the air is blown both internally in the abdominal cavity as well as externally, whilst the carcass is hung on the shackle line. This improves the effectiveness and uniformity of cooling [15]. Air pre-cooling offers a great potential of quality improvement (less cross-contamination and better taste), minimizes water consumption and reduces the management of wastewater, thus representing a reduction of cost at the end of the process [16]. Despite this, using air cooling might reduce the carcass weight between $0.8 \%$ and 2.5\% [17]. Nonetheless, air cooling makes fraud more difficult through excessive carcass absorption of water that usually happens in the water immersion pre-cooling system. In Brazil, a carcass should not exceed absorbing more than $8 \%$ of its weight [14]. In both countries, the carcass temperature after pre-cooling must be measured at the thickest portion of the chest, as it has been identified as the point of the carcass that cools at a slowest speed.

As for the injection of marinades and liquid seasoning in carcass, this technique was prohibited in Brazil through Health Information Note No. 08/2010 [18] in order to combat fraud in the processing of broilers. Such a practice is only allowed in special situations, such as in the preparation of carcass and 
special seasoned cuts of special chicken either frozen or cold, turkeys, ducks, teals and Guinea fowl as well as intended carcasses for institutional sales, with the aim of thermal processing. Yet, appropriate labelling is required, showing the words "this product can only be allocated to the consumer after heat processing”. This practice, which before the ban allowed up to $20 \%$ of brine to be present in the carcasses of chicken, duck, mallards and Guinea fowl as well as up to $25 \%$ in turkey carcasses [19], is still allowed in UK. The food labelling regulations of 1996 and the meat products regulation of 2003 control the labelling of poultry products with added water [13].

\subsection{Packaging}

Before packaging, the carcasses are classified according to their weight (from $800 \mathrm{~g}$ to $3,500 \mathrm{~kg}$ ).

Owed to end consumer trends, British slaughterhouses routinely use conventional and vacuum, as well as modified atmosphere by gas mixture packaging. The modified atmosphere gas mixture is to remove most of the residual oxygen present in the package, by introducing a gas mixture in different ratios (mainly nitrogen and carbon dioxide, still keeping up a certain level of oxygen) which serve as bacteriostatic and fungistatic. Currently, carbon dioxide is considered a food additive in Europe and therefore must be declared on the packages of meat in atmospheres where it is present [20]. Thus, the modified atmosphere enables an extended shelf life where the product remains fresher for a long period without freezing. This is more applicable to British condition whose supply chains are shorter, being the product delivered to the retail market faster. High concentration of oxygen in product packed with modified atmosphere by the gas mixture is also being used to combat contamination by Campylobacter, which has shown not to survive in environments with high concentrations of this gas [21]. Campylobacter remains a very significant issue for the poultry industry in Europe. It causes 280,000 cases of illness per year, and despite the best efforts to control the bacterium, the most recent survey revealed it to be present on $70 \%$ of retail chickens [22]. In Brazil, vacuum packaging is widely used aiming at increasing the product's shelf-life. However, there is still a barrier for consumers and businesses to accept the modified atmosphere gas mixture. In the vacuum packaging system, the growth of aerobic microorganisms is prevented by removing oxygen. However, it does not control the growth of anaerobic and/or facultative anaerobic microorganisms.

\section{Conclusions}

This paper has highlighted many similarities and some differences between the slaughter processes of both UK and Brazil, especially: (1) one system is clearly adapted for the more tropical condition whilst the other for the temperate one; (2) there are differences in the handling during transport and waiting of live birds; (3) stunning systems differ in technique and efficiency; (4) in Britain, the pre-cooling system is clearly a water-saving one; (5) there are technological differences in the primary packaging of the final products; (6) as for the legislation, both countries have very similar rulings which in the Brazilian case tend to comply to main external market demands such as it is the case of poultry meat to the European Union.

\section{Recommendations}

It would be worth considering investigating the cage/crate dimensions used in UK to possibly adapt it to the Brazilian case. And managers in the poultry sector and veterinary authorities in Brazil should seriously consider changes in the format of Brazilian cages for adopting the British standard. Besides, the replacement of the current Brazilian system of stunning by electronarcosis for a more advanced and efficient system, such as the one using modified atmosphere is suggested not only due to improved animal welfare but also because of savings in water. 
The practice of pre-cooling by immersion should be replaced for that of pre-cooling by cold air. In Brazil where distances are far between sites of production and markets, the use of modified atmosphere technology could be further explored to ensure better quality of the final product.

\section{References}

[1] Avisite. 2015. "Brazil: Second Largest Producer of Chicken Meat.” Accessed April 22, 2016. http://avisite.com.br/ noticias/index.php?codnoticia=16536. (in Portuguese)

[2] Oliveria, O. N. 2016. "IBGE Says that Pigs and Chickens Have Record Slaughter in 2015.” Empresa Brasil de Comunicação. Accessed April 22, 2016. http://agenciabrasil.ebc.com.br/economia/noticia/2016-03 /ibge-diz-que-suinos-e-frangos-tem-abate-recorde-em-20 15. (in Portuguese)

[3] Eurostat. 2015. "Meat Production Statistics.” Accessed July 05, 2016. http://ec.europa.eu/eurostat/ statistics-explained/index.php/Meat_production_statistics.

[4] UK Legislation. 1991. "Water Industry Act 1991." Accessed July 05, 2016. http://www.legislation.gov.uk/ ukpga/1991/56/contents.

[5] UK Legislation. 2014. "Water Act 2014.” Accessed July 05, 2016. http://www.legislation.gov.uk/ukpga/2014/21 /introduction/enacted.

[6] Department for Food and the Environment (DEFRA). 2014. “Controls on Animal Byproducts.” Accessed July 05, 2016. https://www.gov.uk/government/uploads/ system/uploads/attachment_data/file/69458/pb13688-ani mal-by-products-controls-111130.pdf.

[7] Department for Food and the Environment (DEFRA). "Welfare of Animals during Transport: Advices for Transporters of Poultry.” Accessed July 05, 2016. http://rpawe.oie.int/fileadmin/upload-activities/upload-tra nsport/transporters_of_poultry_-_defra.pdf.

[8] Bailone, R. L., Borra, R. C., Roça, R. O., and Harris, M. 2016. "Animal Welfare Consequences of Broiler Transport: Comparison between a Brazilian Abattoir and a United Kingdom Abattoir.” Presented at the 50th International Society of Applied Ethology Congress, Edinburgh, the United Kingdom, July 12-16, 2016.

[9] European Union. 2009. "Council Regulation (EC) No. 1099/2009 of 24 September 2009 on the Protection of Animals at the Time of Killing.” Official Journal of European Union L303. Accessed November 18, 2009. http://eur-lex.europa.eu/legal-content/EN/ALL/?uri=CEL EX\%3A32009R1099.

[10] European Commission. 1993. “Council Directive 93/119/EC of 22 December 1993 on the Protection of
Animals at the Time of Slaughter and Killing.” Official Journal of European Union L340. Accessed December 22, 1993. http://eur-lex.europa.eu/legal-content/EN/ALL /?uri=celex\%3A31993L0119.

[11] European Commission. 1993. “Council Directive 92/116/EC of 17 December 1992 Amending and Updating Directive 71/118/EEC on Health Problems Affecting Trade in Fresh Poultry Meat." Official Journal of European Union L062. Accessed March 15, 1993. http://faolex.fao.org/cgi-bin/faolex.exe?rec_id=013634\& database=FAOLEX\&search_type=link\&table=result\&lan $\mathrm{g}=$ eng\&format_name=@ERALL.

[12] Gerritzen, M. A., Reimert, H. G. M., Hindle, V. A., Verhoeven, M. T. W., and Veerkamp, W. B. 2013. "Multistage Carbon Dioxide Gas Stunning of Broilers." Poul. Sci. 92 (1): 41-50.

[13] Food Standards Agency (FSA). 2016. "Meat.” Accessed July 07, 2016. http://www.food.gov.uk/business-industry/ meat.

[14] Brazil Ministry of Agriculture, Livestock and Supply. 1998. Technical Regulation of Technical Inspection and Hygiene-Sanitation in Birds. Health Information Note No. 210, Brasília, DF. (in Portuguese)

[15] Barbut, S. 2002. "Primary Processing of Poultry.” In Poultry Products Processing: An Industry Guide, edited by Barbut, S. Boca Raton, FL: CRC Press, 81-107.

[16] Mckee, S. 2001. “Chilling Difference.” Watt Poultry USA 12: $18-24$.

[17] Huezo, R., Smith, D. P., Northcutt, J. K., and Fletcher, D. L. 2007. "Effect of Immersion or Dry Air Chilling on Broiler Carcass Moisture Retention and Breast Fillet Functionality.” J. Appl. Poul. Res. 16 (3): 438-47.

[18] Brazil Ministry of Agriculture, Livestock and Supply. 2010. Suspension of Development and Marketing of Seasoned Meat Product (Carcasses, Cuts and Poultry Products). Health Information Note No. 08, Brasília, 2010. (in Portuguese)

[19] Brazil Ministry of Agriculture, Livestock and Supply. 2003. Technical Regulation of Identity and Quality of Seasoned Birds. Health Information Note No. 89, Brasília, DF. (in Portuguese)

[20] Wilkinson, B. H. P., Janz, J. A. M., Morel, P. C. H., Purchas, R. W., and Endriks, W. H. 2006. "The Effect of Modified Atmosphere Packaging with Carbon Monoxide on the Storage Quality of Master-Packaged Fresh Pork.” Meat Science 73 (4): 605-10.

[21] Faccenda. 2015. “Faccenda Matters.” Accessed July 05, 2016. http://www.faccendafoods.co.uk/.

[22] The Poultry Site. 2015. "Contrasting the Brazilian and UK Poultry Meat Markets.” Accessed October 29, 2015. http://www.thepoultrysite.com/poultrynews/36072/contra sting-the-brazilian-and-uk-poultry-meat-markets/. 